\title{
PPA e Desenvolvimento Inclusivo
}

Jorge Abrahão de Castro²

\section{INTRODUÇÃO}

A estratégia denominada desenvolvimento inclusivo, contida no Plano Plurianual (PPA) 2016-2019, dava sequência a estratégia dos três planos anteriores e reforçava a centralidade da dimensão social do Estado, além de chamar a atenção para o papel da educação. O PPA 2004-2007, o primeiro plano a explicitar essa estratégia inclusiva de desenvolvimento, tomava como base o fortalecimento do mercado interno mediante a conformação de um mercado de massas apoiado em aumentos reais do salário mínimo, políticas de transferência de renda e redução das desigualdades, associados com o controle da inflação. O PPA 2008-2011, apesar do contexto marcado pela eclosão da crise financeira global, deu sequência a esta estratégia ao reforçar o fortalecimento do mercado interno e a aceleração dos investimentos em infraestrutura econômica e social. O PPA 2012-2015 procurou seguir na mesma direção, com destaque para o Brasil Sem Miséria, que pretendia promover a erradicação da pobreza extrema no Brasil e possibilitar a inclusão social e os investimentos em infraestrutura e habitação.

Este artigo procura apresentar e discutir alguns conceitos e relaçóes teóricas que embasaram a opção estratégica dos quatro planos mencionados, em geral denominada desenvolvimento inclusivo, que tinha como elemento principal a centralidade da dimensão social para a ação do Estado.

\section{POLÍTICAS SOCIAIS E DESENVOLVIMENTO}

Para melhor entendimento do papel estratégico de algumas políticas públicas na promoção de um determinado tipo de desenvolvimento, é importante situar alguns conceitos utilizados. Por exemplo, as políticas públicas foram percebidas como o conjunto de políticas, programas e açóes do Estado, diretamente ou por meio de delegaçáo, com o objetivo de enfrentar desafios e aproveitar oportunidades de interesse coletivo. Tais políticas, programas e açôes concretizam-se em transferências de recursos financeiros e na oferta de bens e serviços que atendam às demandas resultantes das disputas políticas acerca do que é ou deveria ser de interesse público.

Esse conceito de política pública pressupóe, portanto, o reconhecimento de que há uma área ou domínio da vida que não é privada ou somente individual. Qualquer que seja a escala, as políticas públicas remetem a problemas que são públicos, em oposição aos problemas privados; e nas sociedades contemporâneas, cabe ao Estado prover políticas públicas que atendam aos anseios da sociedade. Para que as funçóes estatais sejam exercidas com legitimidade é importante haver planejamento, transparência e permanente interação entre governos e sociedade, de forma que sejam pactuados objetivos e metas que orientem a formulação e a implementação das políticas públicas.

1. DOI: http://dx.doi.org/10.38116/bapi27art6

2. Doutor em economia pelo Instituto de Economia da Universidade Estadual de Campinas (IE-Unicamp). Foi diretor na Diretoria de Estudos e Políticas Sociais (Disoc) do Ipea e na Secretaria de Planejamento e Investimentos Estratégicos (SPI) do então Ministério do Planejamento, Orçamento e Gestão (MPOG). 
Foi norteadora a ideia de que o processo de desenvolvimento do país, como a capacidade de determinada sociedade superar os entraves à realização de suas potencialidades, abrange muito mais que o campo de reflexão da economia, incluindo também elementos relativos à análise das relaçóes sociais, das instituiçôes e das dinâmicas ambientais e territoriais. A partir desta perspectiva o desenvolvimento pôde ser abordado em múltiplas dimensôes, sempre levando em consideração as especificidades econômicas, sociais e políticas históricas de cada país.

Dada essa perspectiva, outro elemento ordenador da estratégia da ação estatal foi a compreensão da dimensão social, que tinha nas políticas sociais o eixo principal, sendo composta por um conjunto de políticas setoriais que buscam realizar dois objetivos conjuntos: i) proteção social, que se refere, principalmente, às situaçóes de dependência ou vulnerabilidade, entre as quais: a incapacidade de ganhar a vida por conta própria em decorrência de fatores externos que independem da vontade individual, como o desemprego involuntário; a vulnerabilidade, em virtude do ciclo de vida do ser humano, como são os casos da infância e dos idosos; e as situaçóes de risco, como em caso de acidentes. As políticas públicas envolvidas neste objetivo compreendem aquelas destinadas à previdência social pública, à saúde pública e à assistência social; e ii) promoçáo social, que se refere aos instrumentos que pretendem garantir aos cidadãos oportunidades e resultados mais amplos e mais equânimes de acesso aos recursos e benefícios conquistados pela sociedade em seu percurso histórico. As políticas envolvidas neste objetivo compreendem um vasto espectro de açóes que abarca desde a formação e o desenvolvimento do cidadáo - casos da educação, do acesso à cultura e das políticas de trabalho e renda que buscam a qualificação profissional e a regulação do mercado de trabalho - até a democratização do acesso a ativos - como as políticas voltadas à agricultura familiar, à habitação e à mobilidade urbana. Havia também as políticas transversais, que podiam ter caráter tanto de proteção como de promoção social, como são as ações voltadas para a igualdade de gênero e para a igualdade racial, assim como aquelas destinadas especificamente às etapas do ciclo de vida, como são as políticas para crianças, adolescentes, jovens e idosos, além daquelas voltadas às pessoas com deficiência, LGBT e populaçóes de rua.

Em outra perspectiva analítica que facilita a compreensão das entregas sociais - renda, bens e serviços - à população, percebem-se três tipos de açóes do Estado: i) garantia de renda; ii) garantia da oferta de bens e serviços sociais; e iii) regulação estatal. A atividade do Estado de garantia de renda ocorre principalmente na modalidade transferências monetárias - aposentadorias, pensóes, seguro-desemprego e auxílio monetário a famílias vulneráveis -, que consistem em transferências em dinheiro que os beneficiários podem gastar no mercado segundo suas preferências, sem restriçóes ou determinações políticas. Existem também ações de garantia de renda não monetárias, que buscam ofertar condiçôes a indivíduos e grupos para que possam gerar sua própria renda.

Essas políticas ampliaram de forma expressiva a importância relativa das transferências monetárias das políticas sociais na composição da renda das famílias, em situaçôes de risco ou vulnerabilidade. Nesse sentido, embora as rendas do trabalho continuem majoritárias, o sistema de garantia de renda do Estado permite compensar as perdas de rendimento recompondo a renda familiar.

Outra atividade é a garantia da oferta de bens e serviços sociais, que pode se dar de duas formas: produção - implica a participação direta de organismos estatais na fabricação de bens e oferta de serviços (exemplo: educação pública e saúde); e provisão de bens e serviços - implica, por parte do 
Estado, destinar os recursos financeiros para viabilizar bens e serviços à comunidade que podem ser atendidos pela produção privada.

$\mathrm{Na}$ regulação estatal, o foco reside na fixação de normas que regulem o comportamento dos agentes econômicos privados e públicos. As políticas de regulação ganham importância crescente quanto mais o setor privado se insere na provisão de bens e serviços de importância social. As duas primeiras atividades ocorrem principalmente mediante gastos públicos pelo aparato do Estado e a última envolve poucos gastos e mais recursos de poder para regular o comportamento dos agentes econômicos.

\section{DIMENSÃO SOCIAL DA ESTRATÉGIA DE DESENVOLVIMENTO DOS QUATRO PPAs DO PERÍODO 2004-2019}

Tendo em vista a delimitação da dimensão social e o mix possível de entregas sociais, a estratégia do desenvolvimento inclusivo, observada nos últimos PPAs, tinha como disjuntiva que a priorização e a ampliação da abrangência das políticas públicas sociais levariam a expandir e materializar direitos, mas também viabilizariam a incorporação ao mercado de milhões de pessoas, mediante, por exemplo, as transferências de renda e a oferta de bens e serviços públicos, o que aumentaria o bem-estar e a maior justiça social e dinamizaria a economia. Além disso, em sua atribuição reguladora, a ação do Estado poderia atuar para a redução das desigualdades no interior do mercado de trabalho via elevação do salário mínimo, o que ampliaria a renda disponível e o acesso a bens e serviços sociais, também reforçando o bem-estar e a justiça social. Estes movimentos se retroalimentariam, possibilitando a redução das desigualdades sociais e regionais, o que, além de ser justificável, geraria como subproduto a ampliaçáo do mercado interno.

Outro importante elemento justificador da opção estratégia era a forma esperada de que a inclusão social influenciaria a dimensão econômica, principalmente em três fatores: i) na expansão e na manutençáo do consumo das famílias; ii) na articulação e na promoçáo da agricultura familiar; e iii) na promoção da infraestrutura social. No primeiro fator de influência, que é o consumo das famílias, esperava-se que as políticas sociais pudessem ampliar o poder de compra da população por meio do aumento real do salário mínimo, programas de geração de emprego e renda, programas de transferência de renda e políticas creditícias voltadas à população. É imenso o contingente populacional carente de bens e serviços, que com o acesso à renda teria várias possibilidades de consumo, gerando uma contínua demanda interna. Para esse processo ser exitoso, é preciso que os produtores nacionais, especialmente na indústria, sejam capazes de atender ao acréscimo de demanda decorrente do processo de inclusão social, evitando o risco de a produção estimulada pelo consumo ser feita no exterior, provocando vazamento de renda com impacto náo desprezível nas contas externas.

Em relação ao segundo fator de influência, o desafio maior da política pública seria agregar valor à agricultura familiar, que é responsável por cerca de um terço do valor da produção agrícola, sobretudo pela produção de um grande número de alimentos da cesta básica, garantindo a segurança alimentar da população e gerando emprego e renda no meio rural. Esse processo de fortalecimento da agricultura familiar é indissociável das políticas públicas, em especial a expansão do crédito rural para o pequeno e médio agricultor e a inovação e absorção de conhecimento científico e tecnológico na produção, produzido por instituiçôes públicas de pesquisa. Seria importante que o aumento da produtividade ampliasse a produção em ritmo mais acelerado que a expansão da área plantada. 
O terceiro fator de influência diz respeito à infraestrutura social, como condição necessária para ampliar a oferta de bens e serviços à população. Isso envolveria as políticas voltadas para manutenção, construção e equipamentos das infraestruturas dos sistemas de saúde e educação pública, bem como as políticas para enfrentar o deficit habitacional mediante a provisão de habitação e as políticas para acesso a bens e serviços de saneamento básico essenciais aos indivíduos; e ainda políticas para mobilidade urbana, acessível e sustentável, que promova inclusão social e a redução das desigualdades por meio de um acesso mais igualitário aos serviços básicos e à cidade em geral.

A ampliação dos investimentos em infraestrutura social era vista como central para a consolidação de um mercado interno, uma vez que tais investimentos podem promover a desconcentraçáo territorial do crescimento econômico e da geração de empregos formais, além de gerar muitos empregos diretos, especialmente na cadeia produtiva da construção civil. Seus efeitos multiplicadores favoreceriam a geração de postos de trabalho nos demais ramos de atividades da economia.

Além desses fatores, as compras e aquisições de bens e serviços necessários à efetivação dos objetivos das políticas sociais poderiam funcionar como propulsores de encadeamentos produtivos locais e territoriais, mediante política de conteúdo local, com cláusulas com valores mínimos que maximizariam a participação de setores micro e médio da indústria local em bases competitivas e sustentáveis. Outro exemplo de articulação entre a dimensão social e a econômica poderia ser as políticas públicas de estímulo ao desenvolvimento do complexo industrial da saúde, que representa uma articulação de segmentos produtivos industriais e de serviços, para garantir acesso a medicamentos e produtos de saúde à população.

A dimensão social, portanto, afetaria a demanda agregada diretamente quando os gastos com investimentos em infraestrutura social, transferências de renda e prestação de bens e serviços permitissem a manutenção/alteração da distribuição pessoal e funcional da renda, com consequências para o respectivo padrão de consumo dos indivíduos, famílias e grupos sociais. Em sociedades heterogêneas, a expectativa era que quanto mais amplas fossem as rendas manejadas e destinadas às camadas mais pobres, maior a capacidade de alteração do padrão, gerando a possibilidade de ampliação da demanda agregada, com capacidade de criar um amplo mercado interno de consumo. Em contrapartida, também é importante para a economia a garantia da oferta de bens e serviços sociais, visto que, para sua implementação, trazem consigo a necessidade de aumento dos gastos na contratação de pessoal, construção, manutenção e equipamentos em escolas, hospitais, postos de saúde, compra de livros, medicamentos e outros insumos estratégicos.

Por sua vez, as políticas públicas sociais, principalmente em seu objetivo de ampliação das habilidades, capacidades e inclusão produtiva da população, poderiam se constituir em elementos determinantes para o progresso técnico e para o aumento da produtividade do trabalho, fatores decisivos para o crescimento econômico, além de facilitar a elevação dos salários e a queda da pobreza. Ademais, também poderiam significar melhor distribuição de renda com queda da desigualdade, a depender, no caso, do resultado em termos de ampliação da renda do fator trabalho.

Portanto, o sucesso da opção estratégica de dar centralidade à dimensão social no processo de desenvolvimento aqui discutido brevemente dependeria também do tamanho e da qualidade das políticas públicas envolvidas. Isso porque a abrangência de benefícios, da cobertura e da qualidade dos bens e serviços ofertados à população e o alcance do investimento público em infraestrutura social conduzido pelo Estado tornam-se elementos centrais para se assegurar o direito social, para o 
ritmo de expansão da atividade (crescimento econômico) e também para a qualidade dessa expansão (aumento da produtividade), balanceado pela preservação e uso sustentável do meio ambiente.

\section{REFERÊNCIAS}

BIANCARELLI, A. A era Lula e sua questão econômica principal: crescimento, mercado interno e distribuição de renda. Revista do Instituto de Estudos Brasileiros, São Paulo: RIEB, n. 58, jun. 2014. BIELSCHOWSKY, R. Estratégia de desenvolvimento e as três frentes de expansão no Brasil: um desenho conceitual. Economia e Sociedade, Campinas, v. 21, número especial, p. 729-747, 2012.

. O modelo de desenvolvimento proposto por Lula e Dilma. São Paulo: Brasil Debate, 2014.

BRASIL. Ministério do Planejamento, Orçamento e Gestão. PPA 2012-2015. Brasília, 2011. Disponível em: <https://www.gov.br/economia/pt-br>.

. Congresso Nacional. Subsídios para apreciação do projeto de lei do Plano Plurianual para o período de 2016 a 2019 (PLN no 06/2015). Brasília, 2015a. (Nota Técnica, n. 10).

- Ministério do Planejamento, Orçamento e Gestão. Orientaçóes para elaboraçáo do Plano Plurianual 2016-2019. Brasília, 2015b. Disponível em: <https://www.gov.br/economia/pt-br>.

. Ministério do Planejamento, Orçamento e Gestão. Relatório Anual de Avaliaçáo do PPA 2012-2015: ano-base 2015. Brasília, v. I, 2015c. Disponível em: <https://www.gov.br/economia/pt-br>. CASTRO, J. A. Política social e desenvolvimento no Brasil. Economia e Sociedade, Campinas, v. 21, número especial, p. 1011-1042, dez. 2012.

CASTRO, J. A.; HENRIQUES, W. Estado de bem-estar social: o que nos sugere a experiência internacional. In: CASTRO, J. A.; POCHMANN, M. Brasil, Estado social contra a barbárie. São Paulo: FPA, 2020.

CASTRO, J. A.; OLIVEIRA, M. Políticas públicas e desenvolvimento. In: MADEIRA, L. M. Avaliação de políticas públicas. Porto Alegre: UFRGS/Cegov, 2014.

CHANG, H. J. Chutando a escada: a estratégia do desenvolvimento em perspectiva histórica. São Paulo: Editora UNESP, 2004.

FURTADO, C. Desenvolvimento e subdesenvolvimento. Rio de Janeiro: Editora Fundo de Cultura, 1961. 
